\title{
TEMPERATURA E UMIDADE RELATIVA DO AR NA ESTAÇÃO SECA EM DIFERENTES USOS DO SOLO NO CAMPUS CUIABÁ - BELA VISTA DO IFMT
}

\author{
Nadja Gomes Machado \\ Professora do Instituto Federal de Mato Grosso/IFMT, Doutoranda em Física Ambiental, Linha de Pesquisa: Análise \\ Microclimática em Sistemas Urbanos, E-mail: nadja.machado@blv.ifmt.edu.br \\ Victor Amadeo Friedlander \\ Instituto Federal de Mato Grosso/IFMT, Aluno de Iniciação Científica, Linha de Pesquisa: Análise Microclimática em \\ Sistemas Urbanos, E-mail: victor.friedlander@gmail.com

\section{Luciana Sanches} \\ Professora do Departamento de Engenharia Sanitária e Ambiental/ FAET/ UFMT, Professora do Programa de Pós- \\ Graduação em Física Ambiental, Linha de Pesquisa: Análise Microclimática em Sistemas Urbanos, E-mail: \\ Isanches@ufmt.br

\section{Marcelo Sacardi Biudes} \\ Professor do Instituto de Física/ IF/ UFMT, Professor do Programa de Pós-Graduação em Física Ambiental, Linha de \\ Pesquisa: Análise Microclimática em Sistemas Urbanos, E-mail: marcelo.biudes@gmail.com
}

\section{http://dx.doi.org/10.5902/223611707706}

\section{RESUMO:}

Cuiabá, outrora conhecida por "Cidade Verde" pelos extensos fragmentos de cerrado presentes em toda a área urbana, vem sofrendo uma acelerada atividade imobiliária sem garantias de preservação das áreas verdes. Diante do exposto, o objetivo deste trabalho foi acompanhar as variações temporais e espaciais de temperatura e umidade relativa do ar nos diferentes usos e ocupação do solo do Campus Cuiabá - Bela Vista. As áreas com cobertura vegetal tiveram os menores valores de temperatura do ar e os maiores valores de umidade relativa do ar, enquanto as áreas sem cobertura vegetal tiveram padrão inverso, ou seja, maiores valores de temperatura do ar e menores valores de umidade relativa do ar.

Palavras-chave: Microclima; Cuiabá; Mato Grosso.

\section{ABSTRACT:}

Cuiabá, known as "Green City" by extensive cerrado fragments present in the urban area, has undergone an accelerated real estate activity without guarantees for the preservation of green areas. Thus, the objective was to monitor the temporal and spatial variations of temperature and relative humidity in the different uses and occupation in the Campus Cuiabá - Bela Vista. The vegetation cover had the lowest air temperature and the highest values of relative humidity, while areas without vegetation had an another pattern, that is higher values of air temperature and lower values of relative humidity.

Keywords: Microclimate; Cuiabá City; Mato Grosso State.

\section{1 - INTRODUÇÃO}

A urbanização como fenômeno mundial é um fato recente e crescente (Gomes \& Soares, 2004). No Brasil, a urbanização foi rápida e tem sido desorganizada, acarretando problemas 
econômicos graves, péssima qualidade de vida (Cano, 1989) e, consequentemente na degradação do ambiente (Gomes \& Soares, 2004).

A urbanização desenfreada, sem mecanismos regulatórios e de controle traz consigo, agravamento de práticas predatórias, gerando erosões do solo, enchentes, desabamentos, desmatamentos, poluição do ar e água (Grostein, 2001), e insuficiência dos serviços básicos de saneamento, coleta e destinação adequada do lixo (Gouveia, 1999), assim como mudanças na temperatura (Amorim, 2005).

A urbanização provoca perda de vegetação nativa e, consequentemente mudanças microclimáticas decorrentes das alterações nos balanços energético, hídrico e térmico e nos fluxos aerodinâmicos do ambiente urbano (Maciel et al., 2011). Segundo Ayoade (1998) a composição química da atmosfera sofre modificações de suas propriedades térmicas e hidrológicas e seus parâmetros aerodinâmicos, o que provoca alterações no microclima.

Uma das alterações no microclima urbano é a formação de ilhas de calor. O fenômeno da ilha de calor urbana caracteriza-se pelo aumento da temperatura do ar nas cidades em relação ao meio rural e as áreas menos urbanizadas, em decorrência do denso e compacto conjunto de construções que ocorrem no centro das cidades (Amorim, 2005).

Cuiabá, outrora conhecida por "Cidade Verde" pelos extensos fragmentos de cerrado presentes em toda a área urbana, vem sofrendo uma acelerada atividade imobiliária sem garantias de preservação das áreas verdes. Diante do exposto, o objetivo deste trabalho foi acompanhar as variações temporais e espaciais de temperatura e umidade relativa do ar nos diferentes usos e ocupação do solo do Campus Cuiabá - Bela Vista na estação seca.

\section{2 - MATERIAL E MÉTODOS}

O Campus Cuiabá - Bela Vista (BLV) do Instituto Federal de Mato Grosso (IFMT) está localizado na região oeste da cidade de Cuiabá - MT. O campus apresenta um ambiente heterogêneo, com diferentes padrões de uso e ocupação do solo, dentre os quais se podem destacar áreas impermeabilizadas, gramado, solo descoberto e vegetação nativa. Portanto, as áreas escolhidas para serem estudadas foram: corredor de salas de aula, asfalto de acesso interno, quadra poliesportiva coberta, solo exposto, grama e mata com vegetação reflorestada há 10 anos. Os dados foram coletados a cada 15 dias às $8 \mathrm{~h}, 14 \mathrm{~h}$ e $20 \mathrm{~h}$ no período de abril a setembro de 2012. A temperatura e umidade relativa do ar foram medidas por um termohigrômetro (modelo HT4000).

\section{3 - RESULTADOS E DISCUSSÕES}

A precipitação anual foi de $1599,87 \mathrm{~mm}$. Abril, junho, julho, agosto e setembro foram os meses que apresentaram menor precipitação (Figura 01). A estação seca ocorre de abril a setembro em Cuiabá (MAITELLI, 1994). 


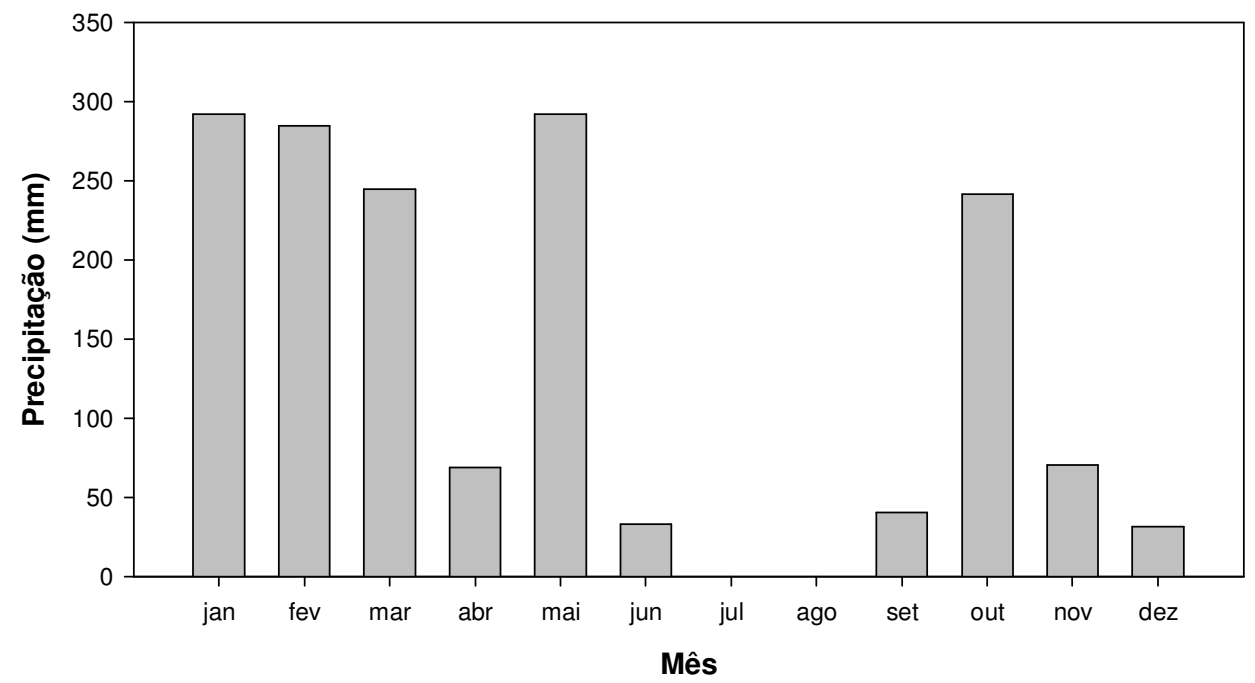

Figura 01 - Precipitação mensal de Cuiabá/MT, 2012. Fonte: Instituto Nacional de Meteorologia (INMET)

A temperatura média anual do ar foi de $29,1^{\circ} \mathrm{C}$ e a umidade relativa média anual foi de $58,3 \%$ no campus BLV/IFMT no período de março até outubro de 2012. A maior temperatura do ar ocorreu em abril e a menor em julho (Figura 02a). A maior umidade relativa do ar ocorreu em junho e a menor em julho (Figura 02b). Em geral, as maiores temperaturas foram medidas às $14 \mathrm{~h}$ e as menores às $8 \mathrm{~h}$ (Figura 02c); enquanto que as maiores umidades relativas do ar foram medidas às $20 \mathrm{~h}$ e as menores às $14 \mathrm{~h}$ (Figura $02 \mathrm{~d}$ ).
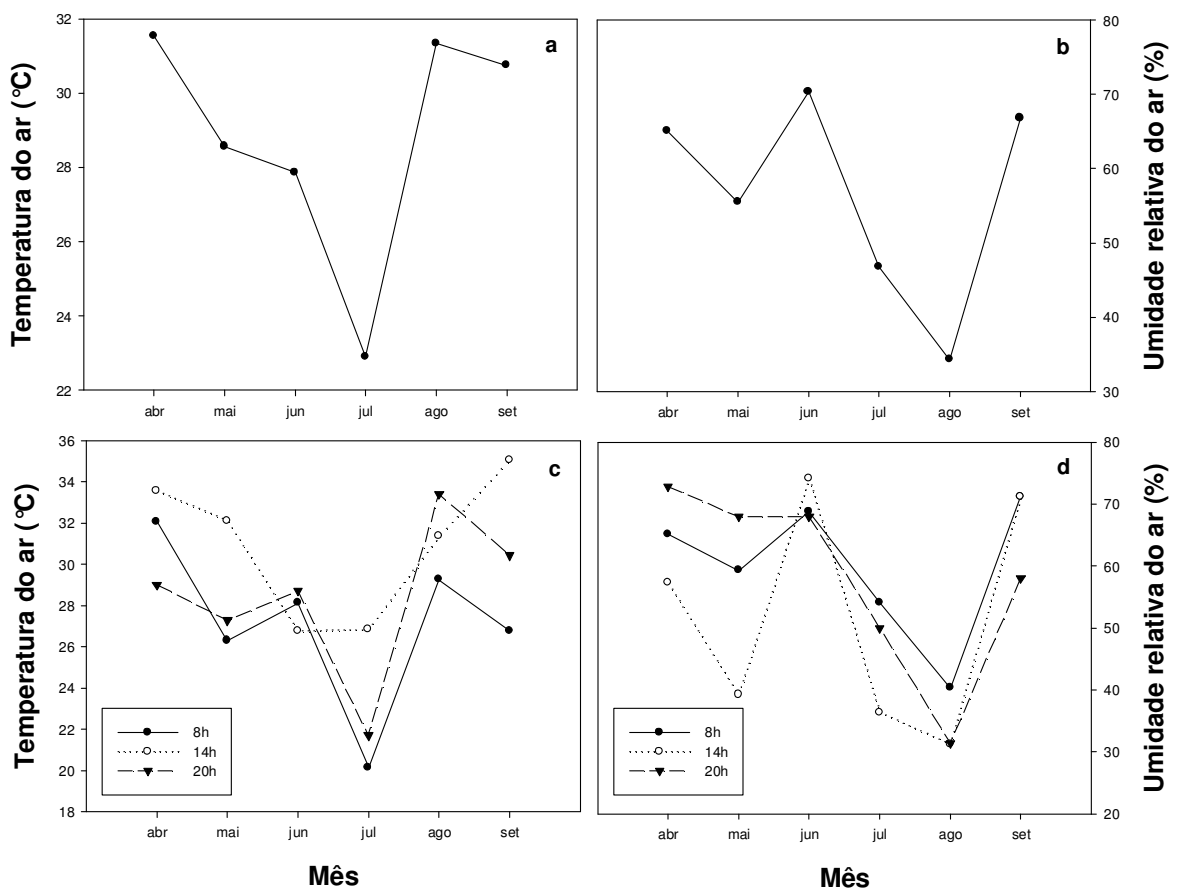

Figura 02 - Média mensal ( $a$ e $b$ ) e média horária $(c$ e $d$ ) da temperatura e umidade relativa do ar no Campus Cuiabá - Bela Vista (BLV) do Instituto Federal de Mato Grosso (IFMT) na estação seca, 2012 
A menor temperatura média foi de $27,4^{\circ} \mathrm{C}$ da mata (Figura 03a) e o maior valor médio foi de $28,2^{\circ} \mathrm{C}$ no solo exposto; enquanto que a menor umidade relativa média foi de $60,4 \%$ no asfalto e a maior foi de $63,7 \%$ (Figura 03b). A umidade relativa do ar ficou abaixo de $30-40 \%$ no mês de agosto. Vale a pena ressaltar que, a umidade do ar abaixo de $20 \%$ é considerada prejudicial à saúde segundo a OMS (Organização Mundial de Saúde).

Com relação às médias horárias de temperatura e umidade relativa do ar, o padrão geral foi:

(i) às $8 \mathrm{~h}$, a mata apresentou os menores valores médios de temperatura do ar (Figura 03c) e os maiores valores médios de umidade relativa do ar (Figura 03d), enquanto que, o solo exposto apresentou os maiores valores de temperatura e os menores de umidade relativa do ar;

(ii) às $14 \mathrm{~h}$, os menores valores médios de temperatura ocorreram no corredor e os maiores valores no solo exposto (Figura 03e), enquanto que, os menores valores de umidade relativa do ar ocorreram na quadra e os maiores valores na mata (Figura 03f); e

(iii) às $20 \mathrm{~h}$, os menores valores médios de temperatura ocorreram na mata e os maiores valores no corredor (Figura 03g), enquanto que, os menores valores de umidade relativa do ar ocorreram no corredor e os maiores valores na mata (Figura 03h). 
Rev. Elet. em Gestão, Educação e Tecnologia Ambiental (e-ISSN: 2236-1170)
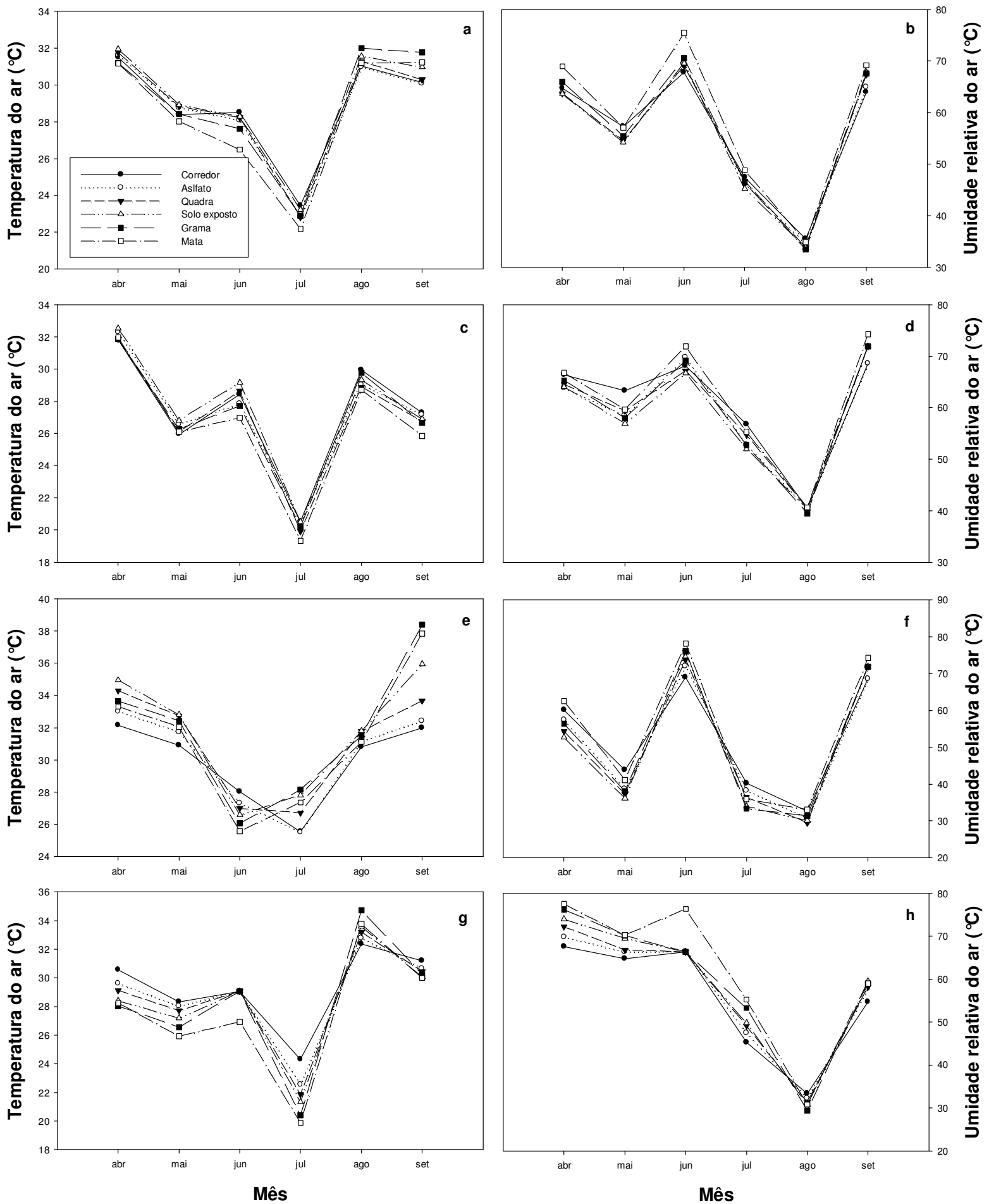

Figura 03 - Média mensal ( $a$ e $b$ ) e média horária da temperatura e umidade relativa do ar às 8 h ( $c$ e $d$ ), $14 \mathrm{~h}$ ( $e$ e $f$ ) e $20 \mathrm{~h}$ ( $g$ e $h$ ) em diferentes usos do solo no Campus Cuiabá - Bela Vista (BLV) do Instituto Federal de Mato Grosso (IFMT) na estação seca, 2012.

As diferenças de temperatura e umidade relativa do ar nos horários e meses de coleta caracterizaram uma variação espaço-temporal. Alves \& Biudes (2012) também encontraram 
variação espaço-temporal da temperatura e umidade relativa do ar no Campus da Universidade Federal de Mato Grosso (UFMT) em Cuiabá. Alves e Specian (2009) também encontraram em 4 pontos da área urbana de Iporá-GO maiores temperaturas em locais mais urbanizados. Os resultados de Oliveira et al. (2009) corroboram os resultados deste trabalho ao apresentarem dados em que a temperatura e umidade relativa do ar tiveram valores superiores na região central (mais construções, menos vegetação) aos dos valores encontrados na região rural (menos construções, mais vegetação) de Cuiabá.

\section{4-CONCLUSÕES}

As áreas com cobertura vegetal tiveram os menores valores de temperatura do ar e os maiores valores de umidade relativa do ar, enquanto as áreas sem cobertura vegetal tiveram padrão inverso, ou seja, maiores valores de temperatura do ar e menores valores de umidade relativa do ar. Portanto, observa-se a urgente necessidade de se planejar a área de estudo em relação ao seu ambiente climático em Cuiabá que apresenta estação seca severa, com baixa umidade relativa do ar.

\section{5 - AGRADECIMENTOS}

O segundo autor agradece ao Programa de Iniciação Científica (PROIC) do Instituto Federal de Mato Grosso (IFMT) pela concessão de bolsa de iniciação científica.

\section{6 - REFERÊNCIAS BIBLIOGRÁFICAS}

ALVES, E.D.L. \& BIUDES, M.S. 2012. Padrões da temperatura do ar e da umidade relativa: estudo de caso no campus de Cuiabá da Universidade Federal de Mato Grosso. Boletim de Geografia 30 (3): 5-16.

ALVES, E.D.L. \& SPECIAN, V. 2009. Contribuição aos estudos do clima urbano: variação térmica e higrométrica em espaços intra-urbanos. Revista Mercator 8 (17): 181-191.

AMORIM, M.C.C.T. 2005. Ilhas de calor em Birigui/SP. Revista Brasileira de Climatologia 1(1): 121130.

AYOADE, J.O. Introdução à Climatologia para os Trópicos. Rio de Janeiro: Bertrand Brasil, 1998.

CANO, W. 1989. Urbanização: sua crise e revisão de seu planejamento. Revista de Economia Política 9 (1): 62-82.

GOMES, M.A.S. \& SOARES, B.R. 2004. Reflexões sobre a qualidade urbana. Estudos Geográficos 2 (2): 21-30.

GOUVEIA, N. 1999. Saúde e meio ambiente nas cidades: desafios da saúde ambiental. Saúde e Sociedade 8 (1): 49-61.

GROSTEIN, M.D. 2001. Metrópole e expansão urbana: a persistência de processos insustentáveis. São Paulo em Perspectiva 15 (1): 13-19. 
MACIEL, C.R., NOGUEIRA, M.C.J.A. \& NOGUEIRA, J.S. 2011. Cobertura do solo e sua influência na temperatura de microclimas urbanos na cidade de Cuiabá-MT. Caminhos de Geografia 12 (38): 40 57.

MAITELLI, G.T. 1994. Uma Abordagem Tridimensional de Clima Urbano em Área Tropical Continental. O Exemplo de Cuiabá - MT. Tese de Doutorado, São Paulo: Faculdade de Filosofia e Ciências Humanas/Universidade de São Paulo.

OLIVEIRA, A.S., SANTOS, F.M.M., NOGUEIRA, M.C.J.A., DURANTE, L.C. \& NINCE, P.C.C. 2009. Análise da variação de temperatura e umidade em função das características de ocupação do solo em Cuiabá - MT. Engenharia Ambiental 6(1): 240-251.

Identificação dos Autores:

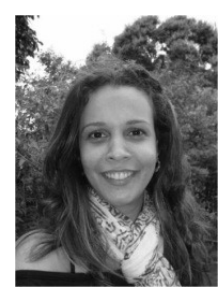

Nadja Gomes Machado

Graduação em Biologia pela Universidade Federal de Mato Grosso/ UFMT;

Professora Efetiva do Instituto Federal de Mato Grosso/ IFMT;

Doutoranda pelo Programa de Pós Graduação em Física Ambiental/ PPGFA/ UFMT, Linha de Pesquisa: Análise

Microclimáticas em Sistemas Urbanos, E-mail: nadja.machado@blv.ifmt.edu.br

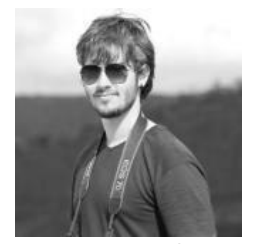

Victor Amadeo Friedlander

Aluno de Ensino Médio Integrado ao Curso Técnico em Meio Ambiente do Instituto Federal de Mato Grosso/ IFMT; Bolsista de Iniciação Científica pelo Programa do Instituto Federal de Mato Grosso/ IFMT;

Linha de Pesquisa: Análise Microclimática em Sistemas Urbanos, E-mail: victor.friedlander@gmail.com 


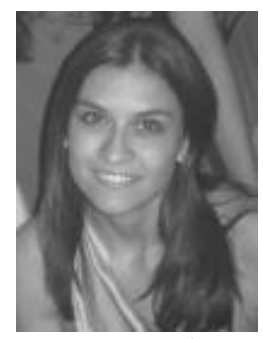

Luciana Sanches

Graduação em Engenharia Sanitária pela Universidade Federal de Mato Grosso/ UFMT;

Professora Efetiva do Departamento de Engenharia Sanitária e Ambiental/ FAET/ UFMT;

Professora do Programa de Pós-Graduação em Física Ambiental, Linha de Pesquisa: Análise Microclimática em Sistemas Urbanos, E-mail: Isanches@ufmt.br

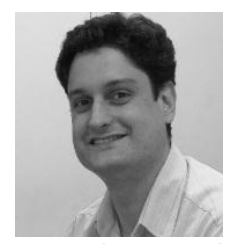

Marcelo Sacardi Biudes

Graduação em Licenciatura Plena em Física pela Universidade Federal de Mato Grosso/ UFMT;

Professor Efetivo do Instituto de Física/ UFMT;

Professor do Programa de Pós Graduação em Física Ambiental/ PPGFA/ UFMT, Linha de Pesquisa: Análise Microclimática em Sistemas Urbanos, E-mail: marcelo.biudes@gmail.com 